\title{
Polymorphisms of vitamin D receptor gene Taql susceptibility of prostate cancer: a meta-analysis
}

\author{
This article was published in the following Dove Press journal: \\ OncoTargets and Therapy \\ I March 2016 \\ Number of times this article has been viewed
}

\author{
Xiawei Fei' \\ Nannan Liu ${ }^{2}$ \\ Huifeng $\mathrm{Li}^{\prime}$ \\ Yanting Shen ${ }^{3}$ \\ Jianming Guo ${ }^{1,4}$ \\ Zhenqi Wu' \\ 'Department of Urology Surgery, \\ Qingpu Branch of Zhongshan Hospital \\ Affiliated to Fudan University, \\ Shanghai, ${ }^{2}$ Department of Clinical \\ Laboratory, The Third Affiliated \\ Hospital of Suzhou University, \\ Changzhou, Jiangsu, ${ }^{3}$ Research Center \\ for Learning Science, Southeast \\ University, Nanjing, ${ }^{4}$ Department of \\ Urology Surgery, Zhongshan Hospital \\ Affiliated to Fudan University, \\ Shanghai, People's Republic of China
}

Correspondence: Zhenqi Wu Department of Urology Surgery, Qingpu Branch of Zhongshan Hospital Affiliated to Fudan University, The Seventh Building 9c, No II 58, East-Park Road, Qingpu District, Shanghai, People's Republic of China

Tel +86 2I 697| 9190 ext 7920

Email zhenqi_wul976@sina.com
Objective: Many studies have investigated the association of the vitamin D receptor gene TaqI polymorphism with prostate cancer ( $\mathrm{PCa}$ ) risk. However, the evidence is inadequate to draw robust conclusions. To shed light on these inconclusive findings, we conducted a meta-analysis.

Materials and methods: We searched PubMed for eligible articles. The relevant data were abstracted by two independent reviewers with the Stata 11.0 software.

Results: A total of 27 studies were included. The pooled outcomes indicated that the TaqI genetic polymorphisms were significantly associated with the risk of $\mathrm{PCa}$ ( $\mathrm{T}$ vs t allele: odds ratio $[\mathrm{OR}]=1.11,95 \%$ confidence interval $[\mathrm{CI}]=1.03-1.21, P=0.008$; TT vs tt: $\mathrm{OR}=1.19,95 \%$ $\mathrm{CI}=1.01-1.42, P=0.040$; $\mathrm{TT}+\mathrm{Tt}$ vs tt: $\mathrm{OR}=1.18,95 \% \mathrm{CI}=1.02-1.38, P=0.031$ ), especially in the Asian population ( $\mathrm{T}$ vs $\mathrm{t}$ allele: $\mathrm{OR}=1.11,95 \% \mathrm{CI}=1.03-1.21, P=0.008$; $\mathrm{TT} / \mathrm{Tt}$ vs $\mathrm{tt}$ : $\mathrm{OR}=1.93,95 \% \mathrm{CI}=1.02-3.66, P=0.043$ ). In the tumor stage stratified analyses, the pooled results showed no significant difference in genetic polymorphisms between the local tumor group and the control group or between the local tumor group and the advanced tumor group. However, the genotypes TT and TT/Tt were significantly higher in the advanced PCa group compared to the control group ( $\mathrm{T}$ vs t allele: $\mathrm{OR}=1.20,95 \% \mathrm{CI}=1.01-1.42, P=0.040$; TT vs tt: $\mathrm{OR}=1.34$, $95 \% \mathrm{CI}=1.08-1.67, P=0.009$; TT/Tt vs tt: $\mathrm{OR}=1.28,95 \% \mathrm{CI}=1.05-1.56, P=0.015)$.

Conclusion: The vitamin D receptor gene TaqI allele polymorphism might be associated with a PCa risk, especially in Asians, which might provide new clues for the pathogenesis research and clinical diagnosis of $\mathrm{PCa}$ in the future.

Keywords: vitamin D receptor, polymorphisms, prostate cancer, meta-analysis

\section{Introduction}

Prostate cancer $(\mathrm{PCa})$ is the second-most frequently diagnosed cancer in males around the world. It is also one of the leading causes of cancer death among men of all races. ${ }^{1}$ Its etiology has remained unclear, and few risk factors have been established for PCa other than older age, a positive family history, and race. $^{2}$ Some previous epidemiological studies suggested that low serum levels of the vitamin D receptor (VDR) might be a risk factor for PCa. ${ }^{3,4}$ Such low levels could be recognized by 1 alpha, 25-dihydroxyvitamin $\mathrm{D}_{3}$ - active form of vitamin $\mathrm{D}-$ and its analogs, and through the interaction between these substances, the tumor cell growth cycle could be fixed in the G1 phase, leading to stagnation of the tumor cells. ${ }^{5}$ However, the mechanism responsible for reduced VDR expression is still not known.

Recently, some studies have shown that VDR gene polymorphisms have functional significance for the stability of mRNA and the protein translation efficiency and may be responsible for the reduced VDR level. ${ }^{6,7}$ The human VDR gene is located on chromosome $12 \mathrm{q} 13.11$ and consists of 14 exons spanning $\sim 75 \mathrm{~kb} \cdot{ }^{8,9}$ It is highly polymorphic with at least 618 variants reported, most of which are either undetectable or present 
at a low frequency in the general population, according to the dbSNP database. ${ }^{10}$

TaqI is one of the most extensively studied SNP and is located in exon 9 of the VDR gene. Several previous studies have suggested that TaqI might alter VDR mRNA levels through regulation of mRNA stability and be associated with a PCa risk. ${ }^{11}$ A number of case-control studies were conducted to investigate the association between the TaqI and the risk of PCa. However, existing evidence is inadequate to draw robust conclusions because the results are not consistent and most studies were generally small. Three published meta-analyses have been reported, but no positive conclusions were given. ${ }^{11-13}$ Subsequently, four new studies have provided additional data on the association between TaqI and PCa risk. ${ }^{14-17}$ Therefore, to shed light on these inconclusive findings, we used the new data to conduct a meta-analysis to revisit the association between the VDR TaqI polymorphism and the risk and characteristics of PCa.

\section{Materials and methods}

\section{Search strategy}

We searched the PubMed and Web of Science databases up to September 8, 2015, for relevant studies about the association of VDR gene TaqI polymorphism and PCa without language restrictions. The search terms included polymorphism, vitamin $\mathrm{D}$ receptor, vitamin $\mathrm{D}_{3}$ receptor, 1,25dihydroxyvitamin $\mathrm{D}_{3}$ receptor, calcitriol receptor, $\mathrm{VDR}$, and $\mathrm{PCa}$, prostate neoplasm, prostate tumor, prostate carcinoma, or prostatic neoplasm.

\section{Inclusion/exclusion criteria}

The title, abstract, and full text of the candidate studies were independently screened by two reviewers. A study was included when all of the following criteria were met: 1) A nonfamilial case-control and cohort study that examined the association between VDR polymorphism and PCa risk with genotyping data for TaqI was included. 2) A study that used men with benign prostatic hyperplasia was included, but a study based on family or pedigree was excluded because of consideration of disease specificity and genetic linkage. 3) A study on localized PCa: confined within the prostate, stages T1-T2 or stages A-B; advanced PCa: extraprostatic or metastatic cancer involving lymph nodes or other organs, stages T3-T4 or stages C-D was included. 4) A study that had complete data or data that could be used to calculate an odds ratio (OR) and a 95\% confidence interval $(95 \% \mathrm{CI})$ was included. 5) A study that used men with benign prostatic hyperplasia as a control was included. 6) A case-only study or a study that had incomplete data for the control group was excluded.

\section{Data extraction}

Information was carefully extracted from all eligible publications by two independent reviewers (Fei and Liu), based on the aforementioned inclusion criteria. Any disagreements were arbitrated by discussion with a third reviewer $(\mathrm{Wu})$. The following data were collected from each study: the first author's surname, the year of publication, the study location, the ethnicity, the source of the controls, the laboratory methods used to detect VDR TaqI polymorphism, and the number of cases and controls. The ethnic groups were mainly defined as Caucasian, Asian, and African. For analysis of the risk factors associated with $\mathrm{PCa}$, we divided the clinical stages and Gleason score into the following two groups: a local group and an advanced group as described previously, Gleason score $<7$ and $\geq 7$ groups.

\section{Quality assessment}

We used the Newcastle-Ottawa Scale (NOS) to assess the quality of each eligible study. When an item was met, the study got one point. The NOS runs from zero to nine points. A study was considered high quality if it received more than four points. ${ }^{18}$

\section{Statistical analysis}

The strength of the association between TaqI T/t polymorphism and the risk of $\mathrm{PCa}$ was indicated by an OR with a $95 \%$ CI. The statistical significance of the pooled OR was assessed with the $Z$-test and a $P$-value of $<0.05$ was considered significant. A chi-square-based $Q$-test was conducted to measure the heterogeneity of eligible studies, and the heterogeneity was considered significant if the $P$-value for heterogeneity test was $<0.05$. Subgroup analyses were conducted to identify the possible variables or characteristics that moderated the obtained results. A sensitivity analysis in which one study was excluded at a time was conducted to evaluate the influence of an individual study based on the results. Begg's funnel plot and Egger's regression test were used to evaluate the publication bias (no publication bias was indicated by a two-sided $P$-value $\geq 0.05$ ). All analyses were conducted using the Stata version 11.0 software (StataCorp LP, College Station, TX, USA), and a two-sided $P$-value $\geq 0.05$ indicated no significance.

\section{Results}

\section{Literature search}

The study selection process is shown in Figure 1. The primary literature search identified 507 studies. After the titles and abstracts were screened, 387 studies were excluded; 78 were reviews, meta-analyses, and letters. The full texts of the remaining 42 studies were evaluated further. As a result, 27 studies were included in the meta-analysis. $3,4,6,14-17,19-38$ 


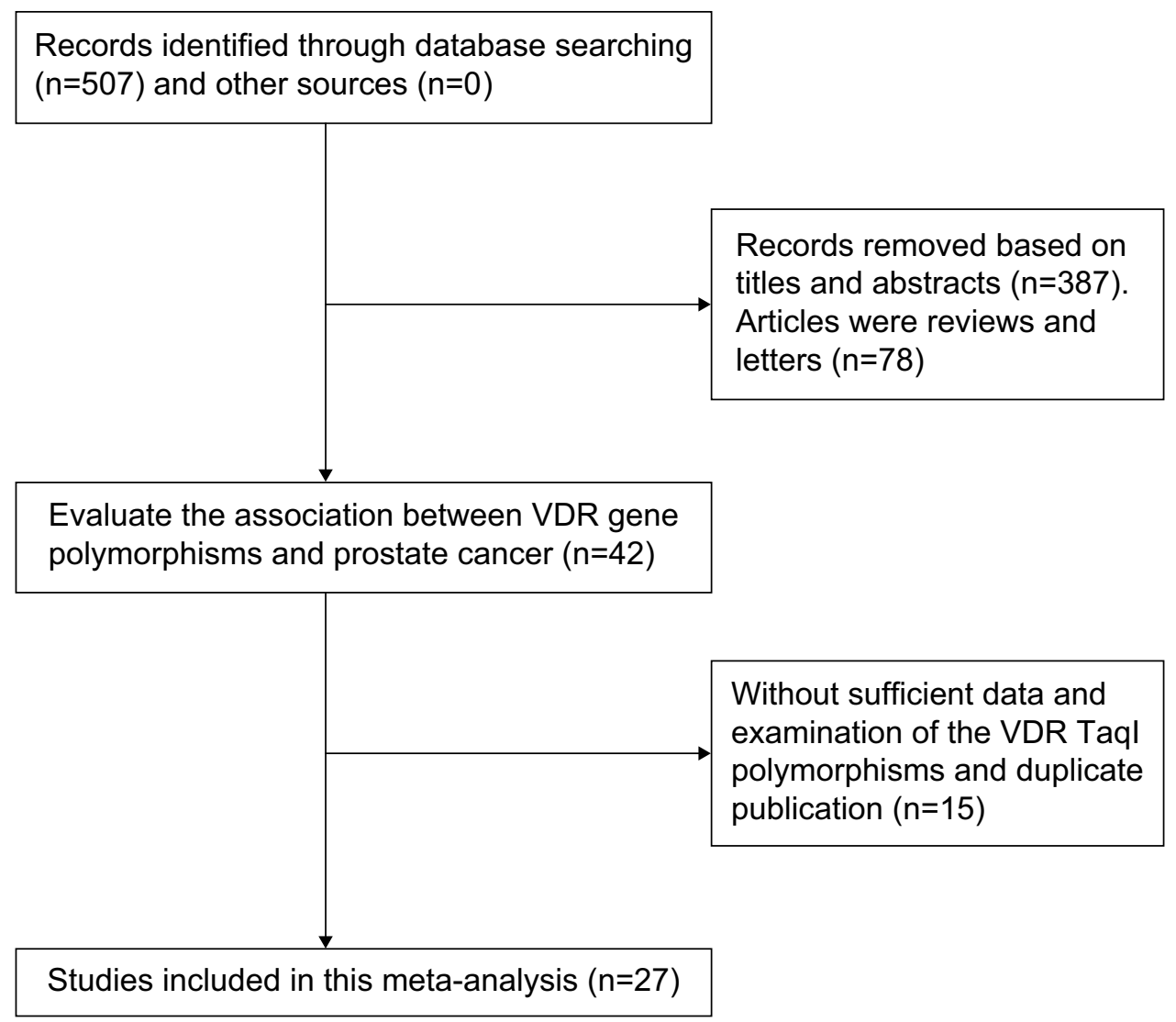

Figure I Study flowchart for the process of selecting the final 27 studies.

\section{Characters and assessments of involved studies}

The 27 eligible studies included 12,276 cases and 13,506 controls and were assessed by the NOS (Table S1). Each had a score of $>4$, which means that all the studies had high quality. The distribution of the VDR gene TaqI polymorphism genotype and allele is shown in Tables 1 and S2.

Meta-analysis of the association of VDR gene Taql polymorphism with PCa risk

The pooled results of 27 relevant studies on the correlation between TaqI polymorphisms and the risk of PCa are presented in Table 2 and Figure 2. The outcome indicated that TaqI genetic polymorphism was significantly associated with the risk of $\mathrm{PCa}$ ( $\mathrm{T}$ vs $\mathrm{t}$ allele: $\mathrm{OR}=1.11,95 \% \mathrm{CI}=1.03-1.21$, $P=0.008$; TT vs tt: $\mathrm{OR}=1.19,95 \% \mathrm{CI}=1.01-1.42, P=0.040$; TT + Tt vs tt: $\mathrm{OR}=1.18,95 \% \mathrm{CI}=1.02-1.38, P=0.031)$.

\section{Meta-analysis of the association of VDR gene Taql} polymorphism with $\mathrm{PCa}$ risk in different populations A previous study showed that ethnicity was a primary risk factor for $\mathrm{PCa} .{ }^{2}$ In order to draw attention to this point, an stratified analysis of ethnicity was performed, ${ }^{3,6,14-17,19-29,31-33,35-38}$ and the pooled results indicated that TaqI genetic polymorphism in the VDR gene was closely linked to the pathogenesis of $\mathrm{PCa}$ among Asian populations ( $\mathrm{T}$ vs t allele: $\mathrm{OR}=1.11$, $95 \% \mathrm{CI}=1.03-1.21, P=0.008$; TT/Tt vs tt: $\mathrm{OR}=1.93,95 \%$ $\mathrm{CI}=1.02-3.66, P=0.043$ ) (Table 3 and Figure 3 ). A sensitivity analyses indicated that an independent study by Jingwi et al was the principal reference for heterogeneity of TaqI polymorphism in the African population. ${ }^{17}$ After the exclusion of this study, the heterogeneity was effectively decreased or was eliminated, and the outcome showed that no statistical significance was found among African or Caucasian populations.

Meta-analysis of the association of VDR gene Taql polymorphism with PCa risk in different tumor stages and Gleason score

We also performed a stratified analysis based on the tumor stage and the Gleason score to delineate the association of VDR gene TaqI polymorphism with PCa risk in more detail. As shown in Table 4 and Figure 4, in the tumor stage stratified analysis, the pooled results showed no significant difference in the genetic polymorphism between local tumor group and the control group or between the local tumor group and the advanced tumor group. However, the genotypes TT and TT/Tt were significantly higher in the advanced 
Table I Detailed association of VDR Taql polymorphism with PCa risk in each individual study

\begin{tabular}{|c|c|c|c|c|c|}
\hline \multirow[t]{2}{*}{$\overline{\text { Study }}$} & \multicolumn{5}{|l|}{ OR (95\% CI) } \\
\hline & $\mathbf{T}$ allele vs $\mathrm{t}$ allele & TT vs tt & TT vs Tt & TT vs (Tt/tt) & (TT/Tt) vs tt \\
\hline Taylor et al ${ }^{6}$ & $1.24(0.88-1.75)$ & $2.36(\mathrm{I} .0 \mathrm{I}-5.53)$ & $0.67(0.39-1.54)$ & $0.86(0.5 \mathrm{I}-\mathrm{I} .47)$ & $3.06(1.41-6.63)$ \\
\hline Kibel et al ${ }^{19}$ & I.37 (0.73-2.57) & $1.69(0.48-5.93)$ & $1.43(0.55-3.70)$ & $1.50(0.62-3.62)$ & $|.4|(0.44-4.5 \mathrm{I})$ \\
\hline Ma et $\mathrm{a}^{20}$ & $1.04(0.86-1.26)$ & $1.09(0.72-1.63)$ & $1.06(0.80-1.40)$ & $1.06(0.81-1.39)$ & $1.05(0.72-1.53)$ \\
\hline Correa-Cerro et $\mathrm{a}^{21}$ & $1.12(0.75-1.68)$ & $0.87(0.37-2.07)$ & $2.00(1.09-3.68)$ & $1.63(0.92-2.89)$ & $0.60(0.27-1.34)$ \\
\hline Watanabe et $\mathrm{a}^{22}$ & $1.09(0.64-1.86)$ & $1.50(0.30-7.60)$ & $1.00(0.54-1.87)$ & $1.05(0.58-1.91)$ & $1.50(0.30-7.57)$ \\
\hline Furuya et $\mathrm{al}^{23}$ & $0.86(0.45-1.64)$ & - & $0.72(0.34-1.52)$ & $0.76(0.36-1.59)$ & - \\
\hline Habuchi et $\mathrm{al}^{24}$ & $1.22(0.84-1.78)$ & $\mathrm{I} .04(0.17-6.3 \mathrm{I})$ & $1.28(0.85-1.94)$ & $1.27(0.85-1.91)$ & $0.99(0.16-5.96)$ \\
\hline Blazer et $\mathrm{a}^{25}$ & $0.97(0.66-1.42)$ & $\mathrm{I} .06(0.49-2.3 \mathrm{I})$ & $0.67(0.37-1.23)$ & $0.77(0.43-1.35)$ & $1.33(0.67-2.67)$ \\
\hline Hamasaki et $\mathrm{al}^{3}$ & $1.82(1.09-3.03)$ & $4.00(0.83-19.35)$ & $1.55(0.84-2.84)$ & $1.75(0.98-3.12)$ & $3.62(0.75-17.39)$ \\
\hline Medeiros et $\mathrm{a}^{26}$ & I.II (0.82-I.49) & $1.54(0.80-2.94)$ & $0.72(0.46-1.14)$ & $0.86(0.56-1.33)$ & $1.87(1.04-3.37)$ \\
\hline Gsur et $\mathrm{al}^{27}$ & $0.78(0.58-1.05)$ & $0.57(0.30-1.06)$ & $0.90(0.58-1.39)$ & $0.80(0.53-1.21)$ & $0.60(0.34-1.07)$ \\
\hline Tayeb et $\mathrm{a}^{28}$ & $0.90(0.48-1.68)$ & $0.80(0.23-2.83)$ & $0.93(0.35-2.5 \mathrm{I})$ & $0.89(0.35-2.27)$ & $0.83(0.27-2.55)$ \\
\hline Tayeb et $\mathrm{al}^{29}$ & $4.54(1.5 I-13.66)$ & $3.91(0.43-35.60)$ & $7.42(1.58-34.90)$ & $6.25(1.69-23.15)$ & $2.65(0.29-23.82)$ \\
\hline Maistro et $\mathrm{al}^{30}$ & $0.74(0.55-1.01)$ & $0.63(0.33-1.23)$ & $0.63(0.4 \mathrm{I}-0.99)$ & $0.63(0.4 I-0.96)$ & $0.80(0.43-1.49)$ \\
\hline Bodiwala et $\mathrm{al}^{3 !}$ & $1.07(0.85-1.35)$ & I.II (0.68-I.82) & I. 17 (0.82-I.67) & $1.15(0.82-1.62)$ & 1.01 (0.65-1.58) \\
\hline Oakley-Girvan et al ${ }^{32}$ & $0.92(0.74-1.16)$ & $0.89(0.55-1.44)$ & $0.86(0.6 \mathrm{I}-\mathrm{I} .20)$ & $0.86(0.63-1.19)$ & $0.97(0.62-\mid .5 I)$ \\
\hline Huang et $\mathrm{a}^{33}$ & I.48 (0.76-2.88) & - & I.5I $(0.76-3.01)$ & - & - \\
\hline John et $\mathrm{al}^{34}$ & $1.19(0.98-1.45)$ & $1.48(1.00-2.21)$ & $1.07(0.80-1.44)$ & $1.17(0.88-1.54)$ & I.43 (0.99-2.05) \\
\hline Andersson et $\mathrm{a}^{35}$ & $0.99(0.7 I-1.36)$ & $0.98(0.52-1.88)$ & $0.96(0.58-1.57)$ & $0.97(0.6 \mathrm{I}-\mathrm{I} .53)$ & $1.01(0.56-1.81)$ \\
\hline Chaimuangraj et $\mathrm{al}^{36}$ & I.0I (0.37-2.73) & - & $0.87(0.30-2.55)$ & $0.93(0.32-2.7 I)$ & - \\
\hline Holick et $\mathrm{al}^{4}$ & $1.13(0.95-1.33)$ & I. $15(0.8 \mathrm{I}-\mathrm{I} .63)$ & $1.36(1.05-1.75)$ & $1.30(1.02-1.65)$ & $0.97(0.70-1.33)$ \\
\hline Onen et $\mathrm{a}^{37}$ & $1.38(0.98-1.95)$ & $1.81(0.87-3.78)$ & I. $46(0.88-2.40)$ & $1.53(0.96-2.45)$ & $1.49(0.75-2.96)$ \\
\hline Onsory et $\mathrm{al}^{38}$ & $1.48(0.96-2.28)$ & $2.30(0.72-7.37)$ & $1.54(0.86-2.74)$ & $1.62(0.93-2.83)$ & $1.88(0.6 \mathrm{I}-5.82)$ \\
\hline Rowland et al ${ }^{14}$ & $1.12(1.00-1.26)$ & $1.283(1.00-1.64)$ & $1.09(0.92-1.28)$ & I.I3 (0.97-I.32) & $1.23(0.98-1.55)$ \\
\hline Hu et $a^{15}$ & $0.77(0.39-1.52)$ & $0.22(0.20-2.45)$ & $0.96(0.44-2.11)$ & $0.84(0.40-1.76)$ & $0.22(0.02-2.45)$ \\
\hline Yousaf et al ${ }^{16}$ & I.47 (0.84-2.57) & $2.84(0.92-8.78)$ & $0.30(0.12-0.75)$ & $0.90(0.44-1.83)$ & $3.68(1.22-11.10)$ \\
\hline Jingwi et al ${ }^{17}$ & $1.53(1.18-1.97)$ & $2.01(1.12-3.59)$ & $1.68(1.17-2.40)$ & $1.74(1.24-2.44)$ & $1.58(0.9 \mathrm{I}-2.76)$ \\
\hline
\end{tabular}

Abbreviations: $\mathrm{VDR}$, vitamin $\mathrm{D}$ receptor; $\mathrm{PC}$, prostate cancer; $\mathrm{OR}$, odds ratio; $\mathrm{Cl}$, confidence interval.

PCa group compared to the control group ( $\mathrm{T}$ vs $\mathrm{t}$ allele: $\mathrm{OR}=1.20,95 \% \mathrm{CI}=1.01-1.42, P=0.040$; TT vs tt: $\mathrm{OR}=1.34$, $95 \% \mathrm{CI}=1.08-1.67, P=0.009$; TT/Tt vs tt: $\mathrm{OR}=1.28,95 \%$ $\mathrm{CI}=1.05-1.56, P=0.015)$.

In the Gleason score stratified analysis, no statistically significant difference in the distribution of the allele and genotype of TaqI polymorphism was evident (TT/Tt vs tt: OR $=1.28,95 \% \mathrm{CI}=0.52-3.13, P=0.584$; TT vs $\mathrm{Tt} / \mathrm{tt}$ : $\mathrm{OR}=0.79,95 \% \mathrm{CI}=0.45-1.37, P=0.396)$. However, the number of articles included ${ }^{15,27,30}$ was too little to draw a robust conclusion. Therefore, further relevant studies should be performed in the future.

\section{Sensitivity analysis}

Sensitivity analyses were performed by the sequential omission of individual studies for all subjects and stratified analyses. Except for the stratified analyses of the association between TaqI polymorphism and PCa risk in an African population, the corresponding pooled ORs were not materially altered in the other stratified analyses, indicating the robustness of the results of this meta-analysis.

\section{Publication bias assessment}

Begg's funnel plot and Egger's test were performed to assess the publication bias in the literature. No evidence

Table 2 Meta-analysis of the association of VDR gene Taql polymorphism with PCa risk

\begin{tabular}{|c|c|c|c|c|c|c|c|c|}
\hline \multirow[t]{2}{*}{ Gene } & \multirow[t]{2}{*}{ Studies } & \multicolumn{3}{|c|}{ Test for overall effect } & \multicolumn{2}{|c|}{ Heterogeneity } & \multicolumn{2}{|l|}{ Public bias } \\
\hline & & OR (95\% CI) & Z-score & $P$-value & $\overline{1^{2}}$ & $P$-value & Begg's test & Egger's test \\
\hline T vs t & 27 & $1.1 I(I .03-1.2 I)$ & 2.64 & 0.008 & $36.9 \%$ & 0.029 & 0.478 & 0.423 \\
\hline TT vs Tt & 27 & $1.07(0.94-1.22)$ & 1.05 & 0.296 & $49 \%$ & 0.002 & 0.835 & 0.550 \\
\hline TT vs tt & 24 & $1.19(1.01-1.42)$ & 2.06 & 0.040 & $34.4 \%$ & 0.051 & 0.673 & 0.724 \\
\hline TT vs (tt/Tt) & 26 & $1.10(0.99-1.24)$ & 1.73 & 0.084 & $41.5 \%$ & 0.015 & 0.692 & 0.949 \\
\hline$(\mathrm{TT} / \mathrm{Tt}) \mathrm{vs} \mathrm{tt}$ & 24 & $1.18(1.02-1.38)$ & 2.15 & 0.031 & $31.4 \%$ & 0.072 & 0.673 & 0.460 \\
\hline
\end{tabular}

Abbreviations: VDR, vitamin $\mathrm{D}$ receptor; $\mathrm{PCa}$, prostate cancer; $\mathrm{OR}$, odds ratio; $\mathrm{Cl}$, confidence interval. 
A Study

Taylor et al ${ }^{6}$ Kibel et $\mathrm{al}^{19}$

Ma et $\mathrm{al}^{20}$

Correa-Cerro et $\mathrm{al}^{21}$

Watanabe et $\mathrm{al}^{22}$

Furuya et $\mathrm{al}^{23}$

Habuchi et $\mathrm{al}^{24}$

Blazer et $\mathrm{al}^{25}$

Hamasaki et al ${ }^{3}$

Medeiros et $\mathrm{al}^{26}$

Gsur et $\mathrm{al}^{27}$

Tayeb et $\mathrm{al}^{28}$

Tayeb et $\mathrm{al}^{29}$

Maistro et $\mathrm{al}^{30}$

Bodiwala et $\mathrm{al}^{31}$

Oakley-Girvan et al ${ }^{32}$

Haung et $\mathrm{al}^{33}$

John et $\mathrm{al}^{34}$

Andersson et $\mathrm{al}^{35}$

Chaimuangraj et $\mathrm{al}^{36}$

Holick et $\mathrm{al}^{4}$

Onen et $\mathrm{al}^{37}$

Onsory et $\mathrm{al}^{38}$

Rowland et al ${ }^{14}$

Hu et al ${ }^{15}$

Yousaf et al ${ }^{16}$

Jingwi et $\mathbf{a l}^{17}$

Overall $\left(I^{2}=36.9 \%, P=0.029\right)$

\section{OR $(95 \% \mathrm{Cl})$}

$1.24(0.88-1.75)$

$1.37(0.73-2.57) \quad 1.41$

$1.04(0.86-1.26) \quad 7.20$

$1.12(0.75-1.68) \quad 2.96$

$1.09(0.64-1.86) \quad 1.88$

$0.86(0.45-1.64) \quad 1.35$

$1.22(0.84-1.78) \quad 3.29$

$0.97(0.66-1.42) \quad 3.19$

$1.82(1.09-3.03) \quad 2.02$

$1.11(0.82-1.49) \quad 4.50$

$0.78(0.58-1.05) \quad 4.53$

$0.90(0.48-1.68) \quad 1.43$

$-4.54(1.51-13.66) \quad 0.50$

$0.74(0.55-1.01) \quad 4.40$

$1.07(0.85-1.35) \quad 6.03$

$0.92(0.74-1.16) \quad 6.20$

$1.48(0.76-2.88) \quad 1.28$

$1.19(0.98-1.45) \quad 7.04$

$0.99(0.71-1.36) \quad 4.03$

$1.01(0.37-2.73) \quad 0.60$

$1.13(0.95-1.33) \quad 7.93$

$1.38(0.98-1.95) \quad 3.73$

$1.48(0.96-2.28) \quad 2.65$

$1.12(1.00-1.26) \quad 9.76$

$0.75(0.38-1.49) \quad 1.22$

$1.47(0.84-2.57) \quad 1.74$

$1.53(1.18-1.97) \quad 5.40$

$1.11(1.03-1.21) \quad 100$

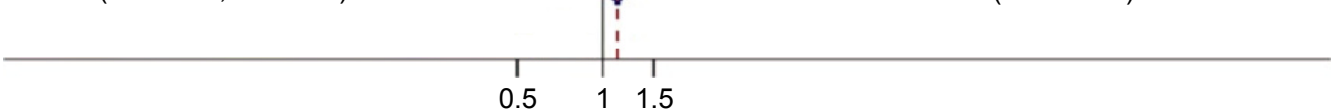

\section{B Study}

Taylor et $\mathrm{al}^{6}$ Kibel et al ${ }^{19}$ Ma et $\mathrm{al}^{20}$ Correa-Cerro et $\mathrm{al}^{21}$ Watanabe et $\mathrm{al}^{22}$ Habuchi et $\mathrm{al}^{24}$ Blazer et $\mathrm{al}^{25}$ Hamasaki et $\mathrm{al}^{3}$ Medeiros et $\mathrm{al}^{26}$ Gsur et $\mathrm{al}^{27}$ Tayeb et al ${ }^{28}$ Tayeb et al ${ }^{29}$ Maistro et $\mathrm{al}^{30}$ Bodiwala et $\mathrm{al}^{31}$ Oakley-Girvan et al ${ }^{32}$ John et $\mathrm{al}^{34}$ Andersson et $\mathrm{al}^{35}$ Holick et al ${ }^{4}$ Onen et $\mathrm{al}^{37}$ Onsory et $\mathrm{al}^{38}$ Rowland et $\mathrm{al}^{14}$ Hu et al ${ }^{15}$ Yousaf et $\mathrm{al}^{16}$ Jingwi et al ${ }^{17}$ Overall $\left({ }^{2}=34.4 \%, P=0.051\right)$
OR $(95 \% \mathrm{Cl}) \quad \%$ weight

\begin{tabular}{ll}
$2.36(1.01-5.53)$ & 3.14 \\
$1.69(0.48-5.93)$ & 1.62 \\
$1.09(0.72-1.63)$ & 7.96 \\
$0.87(0.37-2.07)$ & 3.08 \\
$1.50(0.30-7.60)$ & 1.03 \\
$1.04(0.17-6.31)$ & 0.83 \\
$1.06(0.49-2.31)$ & 3.62 \\
$4.00(0.83-19.35)$ & 1.08 \\
$1.54(0.80-2.94)$ & 4.66 \\
$0.57(0.30-1.06)$ & 4.86 \\
$0.80(0.23-2.83)$ & 1.63 \\
$3.91(0.43-35.60)$ & 0.57 \\
$0.63(0.33-1.23)$ & 4.59 \\
$1.11(0.68-1.82)$ & 6.59 \\
$0.89(0.55-1.44)$ & 6.75 \\
$1.48(1.00-2.21)$ & 8.18 \\
$0.98(0.52-1.88)$ & 4.74 \\
$1.15(0.81-1.63)$ & 9.08 \\
$1.81(0.87-3.78)$ & 3.92 \\
$2.30(0.72-7.37)$ & 1.86 \\
$1.28(1.00-1.64)$ & 11.24 \\
$0.22(0.20-2.45)$ & 1.63 \\
$2.84(0.92-8.78)$ & 1.96 \\
$2.01(1.12-3.59)$ & 5.39 \\
$1.19(1.01-1.42)$ & 100 \\
& \\
\hline &
\end{tabular}

Figure 2 (Continued) 


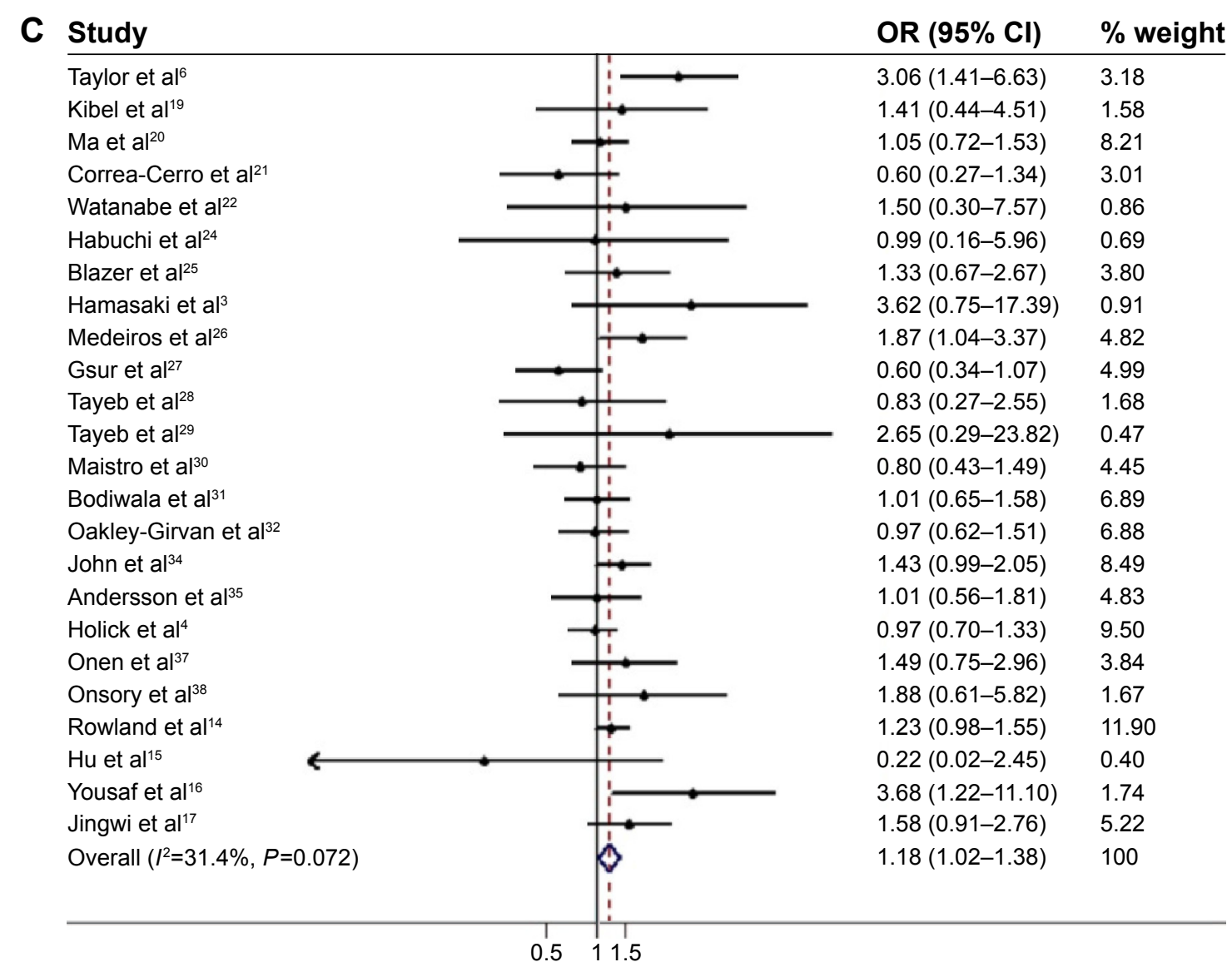

Figure 2 ORs of prostate cancer associated with VDR Taql polymorphisms.

Notes: (A) T vs t, (B) TT vs tt, and (C) (TT/Tt) vs tt. Weights are from random effects analysis.

Abbreviations: $\mathrm{OR}$, odds ratio; VDR, vitamin $\mathrm{D}$ receptor; $\mathrm{Cl}$, confidence interval.

Table 3 Meta-analysis of the association of VDR gene Taql polymorphism with PCa risk in different populations

\begin{tabular}{|c|c|c|c|c|c|c|c|c|}
\hline \multirow[t]{2}{*}{ Gene } & \multirow[t]{2}{*}{ Studies } & \multicolumn{3}{|c|}{ Test for overall effect } & \multicolumn{2}{|c|}{ Heterogeneity } & \multicolumn{2}{|l|}{ Public bias } \\
\hline & & OR (95\% Cl) & Z-score & $P$-value & $I^{2}$ & $P$-value & Begg's test & Egger's test \\
\hline \multicolumn{9}{|l|}{ Caucasian } \\
\hline T vs $t$ & 13 & $1.06(0.97-1.17)$ & 1.31 & 0.191 & $22.9 \%$ & 0.212 & 0.583 & 0.474 \\
\hline TT vs Tt & 13 & $1.02(0.86-\mid .21)$ & 0.24 & 0.898 & $46.2 \%$ & 0.034 & 0.855 & 0.842 \\
\hline TT vs tt & 13 & I. $14(0.97-1.33)$ & 1.55 & 0.122 & $2.1 \%$ & 0.425 & 0.583 & 0.737 \\
\hline $\mathrm{TT}$ vs (tt/Tt) & 13 & $\mathrm{I} .04(0.90-\mathrm{I} .2 \mathrm{I})$ & 0.55 & 0.579 & $36.6 \%$ & 0.090 & 0.360 & 0.814 \\
\hline$(\mathrm{TT} / \mathrm{Tt}) \mathrm{vs} t \mathrm{tt}$ & 14 & $1.13(0.94-1.35)$ & 1.26 & 0.208 & $28.6 \%$ & 0.150 & 0.511 & 0.648 \\
\hline \multicolumn{9}{|l|}{ African } \\
\hline T vs t & 5 & $1.04(0.85-1.28)$ & $0.42^{\mathrm{a}}$ & $0.676^{\mathrm{a}}$ & $0.0 \%$ & 0.956 & $0.806^{\mathrm{a}}$ & $0.917^{\mathrm{a}}$ \\
\hline TT vs Tt & 5 & $0.97(0.74-1.29)$ & $0.18^{a}$ & $0.858^{\mathrm{a}}$ & $0.0 \%$ & 0.558 & $0.22 \mathrm{I}^{\mathrm{a}}$ & $0.854^{\mathrm{a}}$ \\
\hline TT vs tt & 5 & $1.22(0.75-1.97)$ & $0.80^{\mathrm{a}}$ & $0.42 \mathrm{I}^{\mathrm{a}}$ & $0.0 \%$ & 0.844 & $0.806^{\mathrm{a}}$ & $0.935^{\mathrm{a}}$ \\
\hline TT vs (tt/Tt) & 5 & I.0I (0.78-I.32) & $0.08^{a}$ & $0.933^{\mathrm{a}}$ & $0.0 \%$ & 0.805 & $0.462^{\mathrm{a}}$ & $0.78 I^{a}$ \\
\hline$(\mathrm{TT} / \mathrm{Tt}) \mathrm{vs} \mathrm{tt}$ & 6 & $1.32(0.94-1.87)$ & 1.59 & 0.112 & $0.0 \%$ & 0.808 & 0.368 & 0.366 \\
\hline \multicolumn{9}{|l|}{ Asian } \\
\hline T vs $t$ & 9 & $1.27(1.06-1.52)$ & 2.56 & 0.010 & $0.0 \%$ & 0.527 & 0.175 & 0.308 \\
\hline TT vs Tt & 9 & $\mathrm{I} .07(0.8 \mathrm{I}-\mathrm{I} .43)$ & 0.49 & 0.627 & $39.1 \%$ & 0.107 & 0.059 & 0.088 \\
\hline TT vs tt & 6 & $\mathrm{I} .44(0.59-3.5 \mathrm{I})$ & 0.80 & 0.426 & $59.7 \%$ & 0.030 & 0.452 & 0.969 \\
\hline TT vs (tt/Tt) & 8 & $1.19(0.96-1.47)$ & 1.58 & 0.115 & $0.0 \%$ & 0.517 & 0.063 & 0.153 \\
\hline (TT/Tt) vs tt & 6 & $1.93(1.02-3.66)$ & 2.02 & 0.043 & $11.8 \%$ & 0.340 & 0.054 & 0.067 \\
\hline
\end{tabular}

Note: alingwi et al's study ${ }^{17}$ was excluded.

Abbreviations: VDR, vitamin D receptor; $\mathrm{PCa}$, prostate cancer; OR, odds ratio; $\mathrm{Cl}$, confidence interval. 
of publication bias was found for all analyses. Egger's and Begg's tests were not performed for the Gleason stratified analyses and the stage stratified analyses of TT vs tt in the comparison of local tumor group with the control group and the local tumor group with the advanced tumor group due to the small number of included studies.

\section{Discussion}

Various factors contribute to the basic pathology of PCa. Clinical diagnosis of the disease is aided by prostatespecific antigen and biopsy, but none of these methods provide a definitive diagnosis and/or a credible assessment of progression of the disease. ${ }^{39,40}$ Recently, genetic susceptibility to cancer has been a focus of research by the scientific community. The development and progression of PCa are influenced by vitamin D synthesis. ${ }^{3}$ Therefore, the polymorphism of genes that encode key proteins involved in vitamin $\mathrm{D}$ synthesis and metabolism has been chosen as primary candidate genes for PCa susceptibility. Currently, a growing number of studies that have revealed polymorphic variants of the VDR gene were associated with the etiology of PCa. In this meta-analysis, we have analyzed the role of the VDR gene TaqI polymorphism in PCa, which is located in exon 9 and is responsible for the stability of the mRNA.
A Study

Caucasian

Taylor et $\mathrm{al}^{6}$

Ma et $\mathrm{al}^{20}$

Correa-Cerro et $\mathrm{al}^{21}$

Blazer et $\mathrm{al}^{25}$

Medeiros et $\mathrm{al}^{26}$

Gsur et $\mathrm{al}^{27}$

Tayeb et a ${ }^{28}$

Tayeb et al ${ }^{29}$

Bodiwala et a ${ }^{31}$

Oakley-Girvan et al ${ }^{32}$

Andersson et $\mathrm{al}^{35}$

Onen et $\mathrm{al}^{37}$

Rowland et al ${ }^{14}$

Subtotal $\left(I^{2}=22.9 \%, P=0.212\right)$

\section{African}

Kibel et al ${ }^{19}$

Jingwi et $\mathrm{al}^{17}$

Taylor et $\mathrm{al}^{6}$

Blazer et $\mathrm{al}^{25}$

Oakley-Girvan et al ${ }^{32}$

Rowland et al ${ }^{14}$

Subtotal $\left(I^{2}=15.4 \%, P=0.315\right)$
Asian
Watanabe et $\mathrm{al}^{22}$
Furuya et $\mathrm{al}^{23}$
Habuchi et al ${ }^{24}$
Hamasaki et al ${ }^{3}$
Huang et $\mathrm{al}^{33}$
Chaimuangraj et $\mathrm{a}^{36}$
Onsory et $\mathrm{a}^{38}$
Hu et al ${ }^{15}$
Yousaf et al ${ }^{16}$
Subtotal $\left(I^{2}=0.0 \%, P=0.527\right)$
Overall $\left(I^{2}=17.8 \%, P=0.203\right)$

OR $(95 \% \mathrm{Cl})$

$1.24(0.86-1.78) \quad 3.71$

$1.04(0.86-1.26) \quad 9.40$

$1.12(0.75-1.68) \quad 3.10$

$0.99(0.66-1.47) \quad 3.18$

$1.11(0.82-1.49) \quad 5.08$

$0.78(0.58-1.05) \quad 5.13$

$0.90(0.48-1.68) \quad 1.39$

$4.54(1.51-13.66) \quad 0.47$

$1.07(0.85-1.35) \quad 7.38$

$0.94(0.71-1.25) \quad 5.51$

$0.99(0.71-1.36) \quad 4.44$

$1.38(0.98-1.95) \quad 4.05$

$1.11(0.97-1.26) \quad 13.75$

$1.06(0.97-1.17) \quad 66.60$

$1.19(0.19-7.46) \quad 0.17$

$1.53(1.18-1.97) \quad 6.39$

$1.40(0.39-5.00) \quad 0.35$

$0.72(0.18-2.82) \quad 0.31$

$0.98(0.66-1.44) \quad 3.32$

$1.07(0.84-1.38) \quad 6.67$

$1.20(0.99-1.45) \quad 17.21$

$1.09(0.64-1.86) \quad 1.88$

$0.86(0.45-1.64) \quad 1.31$

$1.22(0.84-1.78) \quad 3.50$

$1.82(1.09-3.03) \quad 2.03$

$1.48(0.76-2.88) \quad 1.24$

$1.01(0.37-2.73) \quad 0.57$

$1.48(0.96-2.28) \quad 2.74$

$0.75(0.38-1.49) \quad 1.18$

$1.47(0.84-2.57) \quad 1.72$

$1.27(1.06-1.52) \quad 16.19$

$1.12(1.03-1.21) \quad 100$

Figure 3 (Continued) 


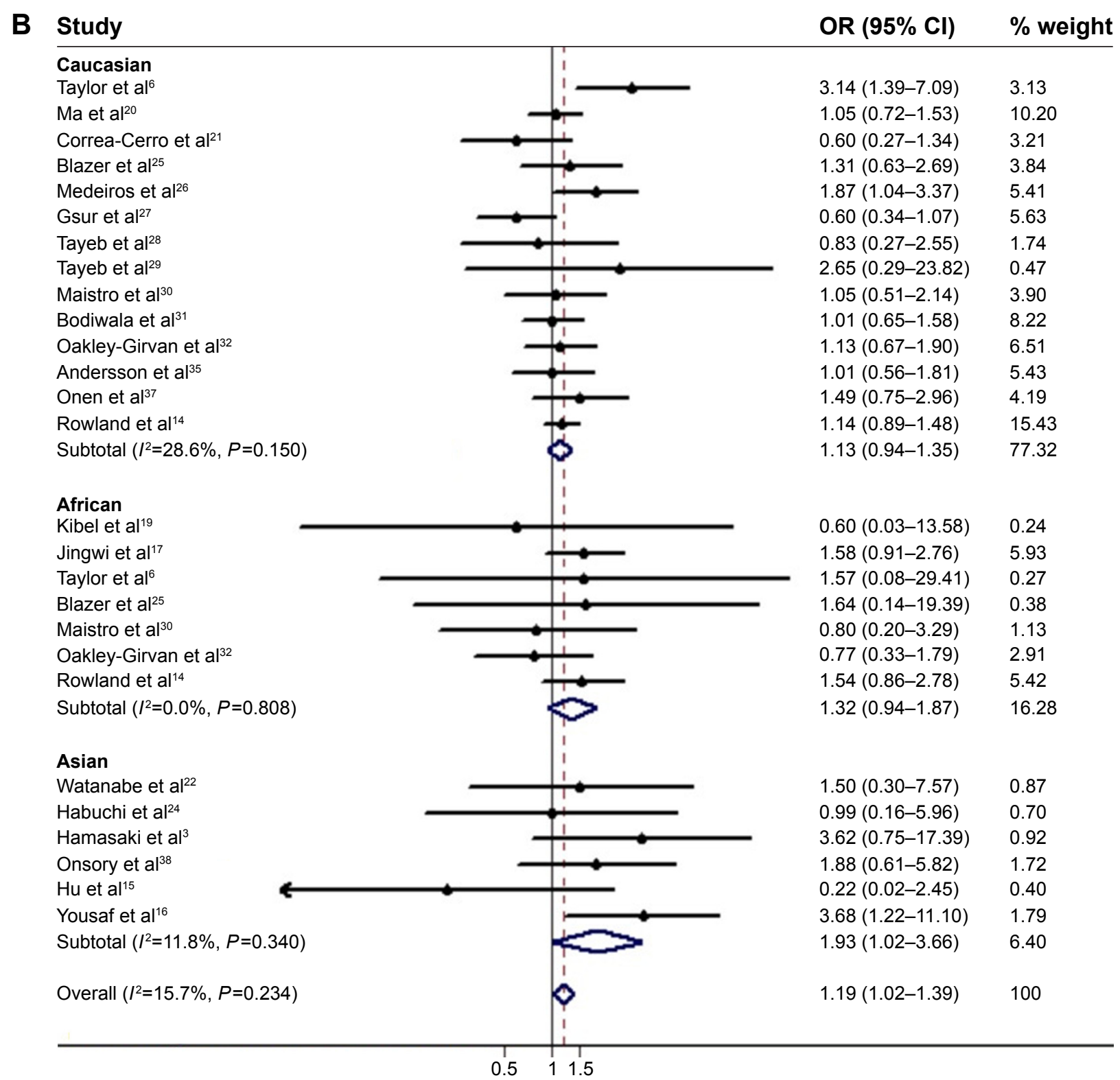

Figure 3 ORs of prostate cancer associated with Taql polymorphism in different populations.

Notes: (A) $\mathrm{T}$ vs $\mathrm{t}$ and $(\mathbf{B})(\mathrm{TT} / \mathrm{Tt})$ vs tt. Weights are from random effects analysis.

Abbreviations: $\mathrm{OR}$, odds ratio; $\mathrm{Cl}$, confidence interval.

We found that a variant TaqI allele ( $\mathrm{t}$ ) was significantly correlated with a reduced risk of $\mathrm{PCa}$, suggesting it might be a protective factor for $\mathrm{PCa}$, which was consistent with a previous meta-analysis. ${ }^{10}$

Ethnicity is an important biological factor that might influence VDR function through gene-gene interaction. In our analysis, the association of TaqI polymorphism with a PCa risk was observed in the Asian population, which was consistent with Yin et $\mathrm{a}^{10}$ Although the underlying mechanism for the observed ethnic difference in the PCa risk must still be elucidated, a tumor-protective effect of the TaqI $\mathrm{t}$ allele in Asians was significantly more pronounced than in the other two ethnic groups, Caucasians and Africans. In the Asian population, a tt genotype carrier had a lower risk of PCa, compared to a TT or TT/Tt genotype.

We also performed tumor stage and Gleason score striated analyses. Differently from Yin et al's study, ${ }^{10}$ we obtained some positive results. We found that the $t$ allele and the tt genotype could reduce the PCa risk when compared with the $\mathrm{T}$ allele, TT genotype, or TT/Tt genotype, indicating that variant the TaqI $t$ allele might indeed be associated with disease progression. However, the Gleason score striated analysis indicated no association between TaqI polymorphism and PCa risk. 
Table 4 Meta-analysis of the association of VDR gene Taql polymorphism with PCa risk in different tumor stages

\begin{tabular}{|c|c|c|c|c|c|c|c|c|}
\hline \multirow[t]{2}{*}{ Stage } & \multirow[t]{2}{*}{ Studies } & \multicolumn{3}{|c|}{ Test for overall effect } & \multicolumn{2}{|c|}{ Heterogeneity } & \multicolumn{2}{|l|}{ Public bias } \\
\hline & & OR (95\% Cl) & Z-score & $P$-value & $I^{2}$ & $P$-value & Begg's test & Egger's test \\
\hline \multicolumn{9}{|l|}{ Local vs control } \\
\hline T vs $t$ & 5 & $1.09(0.95-1.25)$ & 1.18 & 0.237 & $0.0 \%$ & 0.939 & 0.806 & 0.741 \\
\hline TT vs tt & 2 & $1.26(0.9 \mid-1.73)$ & 1.40 & 0.160 & $0.0 \%$ & 0.635 & - & - \\
\hline TT vs Tt & 5 & $0.97(0.80-1.18)$ & 0.32 & 0.752 & $0.0 \%$ & $0.94 I$ & 0.806 & 0.213 \\
\hline TT vs (tt/Tt) & 6 & I.07 (0.88-|.3I) & 0.68 & 0.498 & $3.3 \%$ & 0.395 & 1.000 & 0.885 \\
\hline (TT/Tt) vs tt & 4 & $1.16(0.88-1.53)$ & 1.07 & 0.287 & $0.0 \%$ & 0.451 & 0.734 & 0.442 \\
\hline \multicolumn{9}{|c|}{ Advanced vs control } \\
\hline T vs $t$ & 6 & $1.20(1.01-1.42)$ & 2.05 & 0.040 & $31.5 \%$ & 0.199 & 0.452 & 0.354 \\
\hline TT vs tt & 4 & $1.34(1.08-1.67)$ & 0.63 & 0.009 & $0.0 \%$ & 0.746 & 0.734 & 0.216 \\
\hline TT vs Tt & 6 & $1.15(0.86-1.52)$ & 0.93 & 0.352 & $45.6 \%$ & 0.101 & 0.707 & 0.799 \\
\hline TT vs (tt/Tt) & 7 & I. $17(0.89-1.54)$ & 1.14 & 0.256 & $43.6 \%$ & 0.100 & 0.368 & $0.94 I$ \\
\hline (TT/Tt) vs tt & 6 & $1.28(1.05-1.56)$ & 2.44 & 0.015 & $0.0 \%$ & 0.821 & 0.420 & 0.189 \\
\hline \multicolumn{9}{|c|}{ Local vs advanced } \\
\hline T vs $t$ & 5 & $0.95(0.82-1.10)$ & 0.65 & 0.515 & $0.0 \%$ & 0.536 & 0.462 & 0.191 \\
\hline TT vs tt & 2 & I.02 (0.72-I.45) & 0.13 & 0.896 & $0.0 \%$ & 0.663 & - & - \\
\hline TT vs Tt & 5 & $0.76(0.48-\mid .21)$ & 1.14 & 0.255 & $32.9 \%$ & 0.202 & 0.806 & 0.575 \\
\hline $\mathrm{TT}$ vs (tt/Tt) & 6 & $0.87(0.62-\mid .21)$ & 0.84 & 0.400 & $14.0 \%$ & 0.325 & 0.260 & 0.805 \\
\hline (TT/Tt) vs tt & 4 & I.0I (0.74-I.38) & 0.08 & 0.938 & $0.0 \%$ & 0.628 & 0.734 & 0.054 \\
\hline
\end{tabular}

Abbreviations: VDR, vitamin D receptor; $\mathrm{PCa}$, prostate cancer; $\mathrm{OR}$, odds ratio; $\mathrm{Cl}$, confidence interval.

\section{A Study}

Furuya et al ${ }^{23}$

Blazer et $\mathrm{al}^{25}$

Hamasaki et al ${ }^{3}$

Huang et $\mathrm{al}^{33}$

Rowland et al ${ }^{14}$

John et $\mathrm{al}^{34}$

Overall $\left(I^{2}=31.5 \%, P=0.199\right)$

\section{OR $(95 \% \mathrm{Cl}) \quad \%$ weight}

$0.86(0.43-1.70) \quad 5.74$

$1.02(0.44-2.35) \quad 3.95$

$2.30(1.20-4.39) \quad 6.33$

$\rightarrow 2.40(0.82-7.01) \quad 2.48$

$1.12(0.99-1.27) \quad 46.72$

$1.19(0.98-1.45) \quad 34.79$

$1.20(1.01-1.42) \quad 100$

\begin{tabular}{llll}
\hline 1 & 0.5 & 1 & 1.5
\end{tabular}

B Study

OR (95\% Cl) \% weight

Blazer et $\mathrm{al}^{25}$

Hamasaki et al ${ }^{3}$

John et $\mathrm{al}^{34}$

Rowland et al ${ }^{14}$

Overall $\left(I^{2}=0.0 \%, P=0.746\right)$

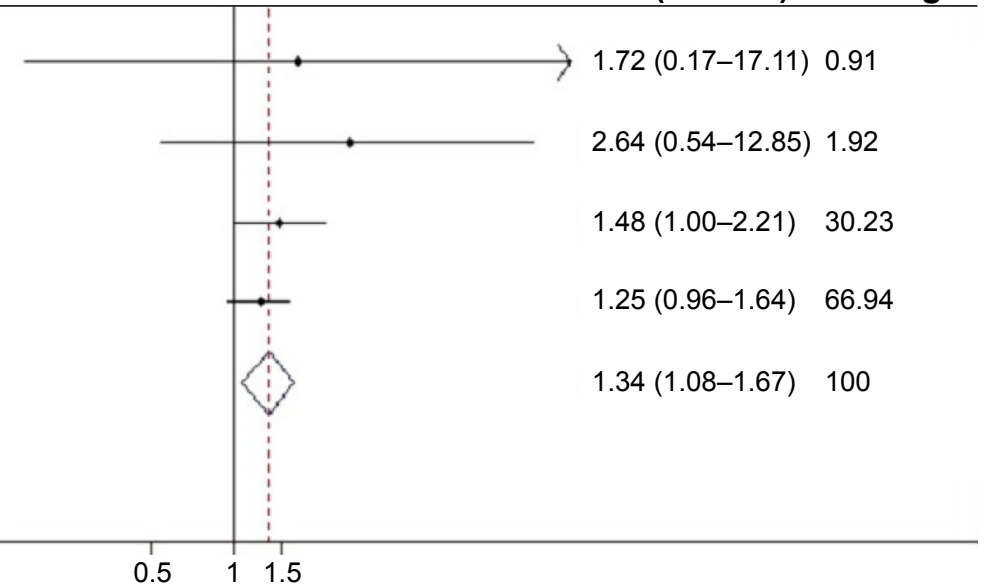

Figure 4 (Continued) 


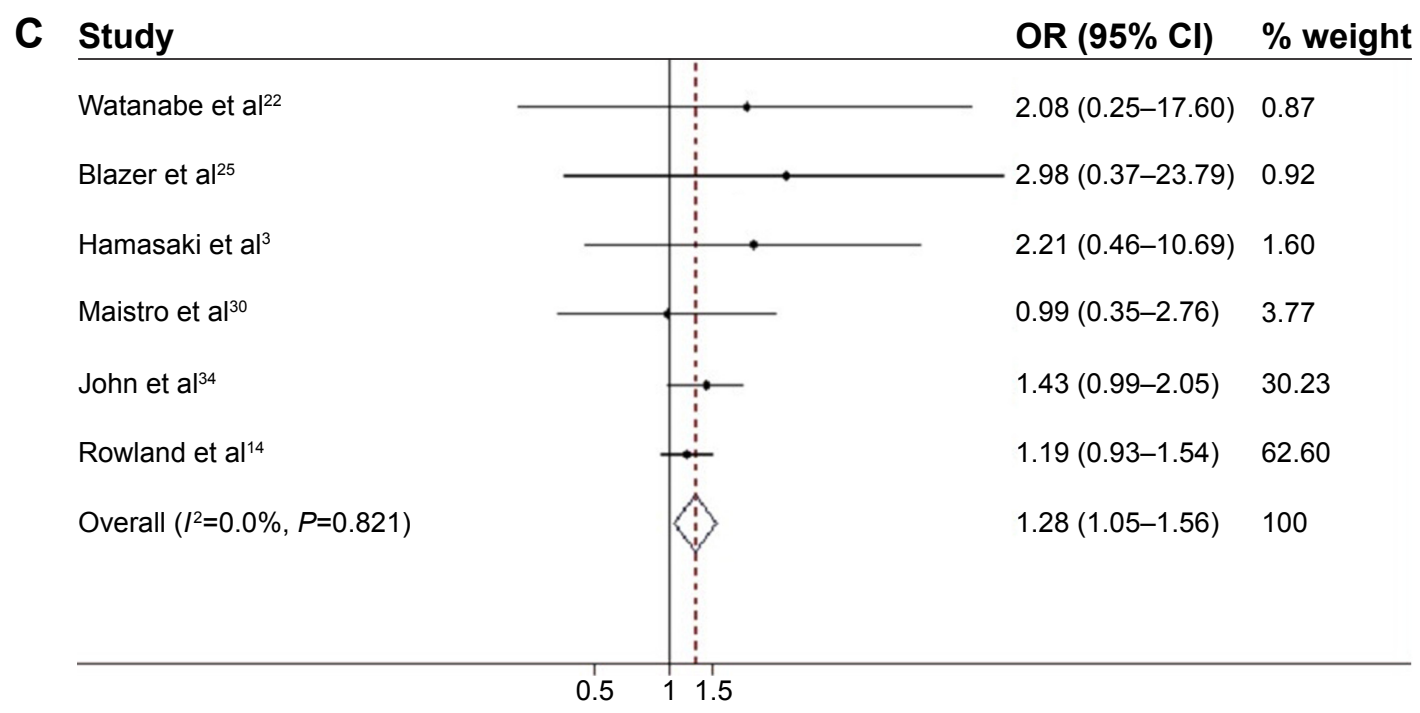

Figure 4 ORs of Taql polymorphism comparing advanced prostate cancer group with control group. Notes: (A) T vs t, (B) TT vs tt, and (C) (TT/Tt) vs tt. Weights are from random effects analysis. Abbreviations: $\mathrm{OR}$, odds ratio; $\mathrm{Cl}$, confidence interval.

\section{Study limitations}

Although our study showed some positive results, this metaanalysis had several limitations that should be taken consideration when assessing the results. First, although we performed subgroup analyses stratified by ethnicity, tumor stage, and the Gleason score, heterogeneity of TaqI polymorphism among the studies still exists, which suggested that other potential confounding factors were present in the included studies, such as genotyping error, selection bias, population-specific genegene or gene-environment interaction, allelic heterogeneity, and chance. ${ }^{41,42}$ Although evidence for heterogeneity exists, the sensitivity analysis indicated that studies contributing to the heterogeneity did not significantly affect the estimate of the overall OR. Second, the overall outcomes were based on unadjusted effect estimates. Although the cases and controls were matched for age, sex, and residence in all studies, these confounding factors could slightly modify the effective estimates and a more precise evaluation would have to be adjusted for the potentially suspicious factors. Third, benign prostate hyperplasia was used as control in some included studies, which could affect the pooled results to a varying degree. Finally, in some pooled analyses such as Gleason score striated analysis, the number of included studies was too small, so further relevant studies should be performed in the future so that a stronger conclusion could be drawn.

\section{Conclusion}

In summary, a strong association was observed between VDR TaqI genetic polymorphism and PCa, and therefore, TaqI genetic polymorphism may be valuable as a biomarker, especially in Asians. Considering that the quality and quantity of the reviewed articles were limited, larger, well-designed studies should be used in the future to further confirm the association between TaqI genetic polymorphism and PCa.

\section{Disclosure}

The authors report no conflicts of interest in this work.

\section{References}

1. Faezeh A, Mehdi KP, Mahsa J, Bahram R. Fruit and vegetable intake in relation to prostate cancer in Iranian men: a case-control study. Asian Pac J Cancer Prev. 2014;15:5317-5324.

2. Shavers VL, Underwood W, Moser RP. Race/ethnicity and the perception of the risk of developing prostate cancer. Am J Prev Med. 2009;37: 64-67.

3. Hamasaki T, Inatomi H, Katoh T, Ikuyama T, Matsumoto T. Clinical and pathological significance of vitamin $\mathrm{D}$ receptor gene polymorphism for prostate cancer which is associated with a higher mortality in Japanese. Endocr J. 2001;48:543-549.

4. Holick CN, Stanford JL, Kwon EM, Ostrander EA, Nejentsev S, Peters U. Comprehensive association analysis of the vitamin D pathway genes, VDR, CYP27B1, and CYP24A1, in prostate cancer. Cancer Epidemiol Biomarkers Prev. 2007;16:1990-1999.

5. Hamasaki $\mathrm{T}$, Inatomi $\mathrm{H}$, Katoh $\mathrm{T}$, et al. $\mathrm{N}$-acetyltransferase-2 gene polymorphism as a possible biomarker for prostate cancer in Japanese men. Int J Urol. 2003;10:167-173.

6. Taylor JA, Hirvonen A, Watson M, Pittman G, Mohler JL, Bell DA. Association of prostate cancer with vitamin D receptor gene polymorphism. Cancer Res. 1996;56:4108-4110.

7. Uitterlinden AG, Fang Y, Van Meurs JB, Pol HA, Van Leeuwen JP. Genetics and biology of vitamin D receptor polymorphisms. Gene. 2004; 338:143-156.

8. Miyamoto K, Kesterson RA, Yamamoto H, et al. Structural organization of the human vitamin D receptor chromosomal gene and its promoter. Mol Endocrinol. 1997;11:1165-1179.

9. Crofts LA, Hancock MS, Morrison NA, Eisman JA. Multiple promoters direct the tissue-specific expression of novel $\mathrm{N}$-terminal variant human vitamin D receptor gene transcripts. Proc Natl Acad Sci U S A. 1998;95: 10529-10534. 
10. Yin M, Wei S, Wei QY. Vitamin D receptor genetic polymorphisms and prostate cancer risk: a meta-analysis of 36 published studies. Int J Clin Exp Med. 2009;2:159-175.

11. Morrison NA, Qi JC, Tokita A, et al. Prediction of bone density from vitamin D receptor alleles. Nature. 1994;367:284-287.

12. Ntais C, Polycarpou A, Ioannidis JP. Vitamin D receptor gene polymorphisms and risk of prostate cancer: a meta-analysis. Cancer Epidemiol Biomarkers Prev. 2003;12:1395-1402.

13. Berndt SI, Dodson JL, Huang WY, Nicodemus KK. A systematic review of vitamin D receptor gene polymorphisms and prostate cancer risk. J Urol. 2006;175:1613-1623.

14. Rowland GW, Schwartz GG, John EM, Ingles SA. Protective effects of low calcium intake and low calcium absorption vitamin D receptor genotype in the California Collaborative Prostate Cancer Study. Cancer Epidemiol Biomarkers Prev. 2013;22:16-24.

15. Hu J, Qiu Z, Zhang L, Cui F. Kallikrein 3 and vitamin D receptor polymorphisms: potentials environmental risk factors for prostate cancer. Diagn Pathol. 2014;22(9):84.

16. Yousaf N, Afzal S, Hayat T, et al. Association of vitamin D receptor gene polymorphisms with prostate cancer risk in the Pakistani population. Asian Pac J Cancer Prev. 2014;15:10009-10013.

17. Jingwi EY, Abbas M, Ricks-Santi L, et al. Vitamin D receptor genetic polymorphisms are associated with PSA level, Gleason score and prostate cancer risk in African-American men. Anticancer Res. 2015;35: 1549-1558.

18. Ownby RL, Crocco E, Acevedo A, John V, Loe-wenstein D. Depression and risk for Alzheimer disease: systematic review, meta-analysis, and meta-regression analysis. Arch Gen Psychiatry. 2006;63:530-538.

19. Kibel AS, Isaacs SD, Isaacs WB, Bova GS. Vitamin D receptor polymorphisms and lethal prostate cancer. J Urol. 1998;160:1405-1409.

20. Ma J, Stampfer MJ, Gann PH, et al. Vitamin D receptor polymorphisms, circulating vitamin D metabolites, and risk of prostate cancer in United States physicians. Cancer Epidemiol Biomarkers Prev. 1998; 7:385-390.

21. Correa-Cerro L, Berthon P, Häussler J, et al. Vitamin D receptor polymorphisms as markers in prostate cancer. Hum Genet. 1999;105: 281-287.

22. Watanabe M, Fukutome K, Murata M, et al. Significance of vitamin D receptor gene polymorphism for prostate cancer risk in Japanese. Anticancer Res. 1999;19:4511-4514.

23. Furuya Y, Akakura K, Masai M, Ito H. Vitamin D receptor gene polymorphism in Japanese patients with prostate cancer. Endocr J. 1999;46: $467-470$.

24. Habuchi T, Suzuki T, Sasaki R, et al. Association of vitamin D receptor gene polymorphism with prostate cancer and benign prostatic hyperplasia in a Japanese population. Cancer Res. 2000;60:305-308.

25. Blazer DG, Umbach DM, Bostick RM, Taylor JA. Vitamin D receptor polymorphisms and prostate cancer. Mol Carcinog. 2000;27:18-23.

26. Medeiros R, Morais A, Vasconcelos A, et al. The role of vitamin D receptor gene polymorphisms in the susceptibility to prostate cancer of a southern European population. J Hum Genet. 2002;47:413-418.
27. Gsur A, Madersbacher S, Haidinger G, et al. Vitamin D receptor gene polymorphism and prostate cancer risk. Prostate. 2002;51:30-34.

28. Tayeb MT, Clark C, Haites NE, Sharp L, Murray GI, McLeod HL. CYP3A4 and VDR gene polymorphisms and the risk of prostate cancer in men with benign prostate hyperplasia. Br J Cancer. 2003;88: 928-932.

29. Tayeb MT, Clark C, Haites NE, Sharp L, Murray GI, McLeod HL. Vitamin D receptor, HER-2 polymorphisms and risk of prostate cancer in men with benign prostate hyperplasia. Saudi Med J. 2004;25: $447-451$.

30. Maistro S, Snitcovsky I, Sarkis AS, da Silva IA, Brentani MM. Vitamin D receptor polymorphisms and prostate cancer risk in Brazilian men. Int J Biol Markers. 2004;19:245-249.

31. Bodiwala D, Luscombe CJ, French ME, et al. Polymorphisms in the vitamin D receptor gene, ultraviolet radiation, and susceptibility to prostate cancer. Environ Mol Mutagen. 2004;43:121-127.

32. Oakley-Girvan I, Feldman D, Eccleshall TR, et al. Risk of early-onset prostate cancer in relation to germ line polymorphisms of the vitamin D receptor. Cancer Epidemiol Biomarkers Prev. 2004;13:1325-1330.

33. Huang SP, Chou YH, Wayne Chang WS, et al. Association between vitamin D receptor polymorphisms and prostate cancer risk in a Taiwanese population. Cancer Lett. 2004;207:69-77.

34. John EM, Schwartz GG, Koo J, Van Den Berg D, Ingles SA. Sun exposure, vitamin D receptor gene polymorphisms, and risk of advanced prostate cancer. Cancer Res. 2005;65:5470-5479.

35. Andersson P, Varenhorst E, Söderkvist P. Androgen receptor and vitamin D receptor gene polymorphisms and prostate cancer risk. Eur J Cancer. 2006;42:2833-2837.

36. Chaimuangraj S, Thammachoti R, Ongphiphadhanakul B, Thammavit W. Lack of association of VDR polymorphisms with Thai prostate cancer as compared with benign prostate hyperplasia and controls. Asian Pac J Cancer Prev. 2006;7:136-139.

37. Onen IH, Ekmekci A, Eroglu M, Konac E, Yesil S, Biri H. Association of genetic polymorphisms in vitamin D receptor gene and susceptibility to sporadic prostate cancer. Exp Biol Med (Maywood). 2008;233: 1608-1614.

38. Onsory K, Sobti RC, Al-Badran AI, et al. Hormone receptor-related gene polymorphisms and prostate cancer risk in North Indian population. Mol Cell Biochem. 2008;314:25-35.

39. Scher HI, Heller G. Clinical states in prostate cancer: toward a dynamic model of disease progression. Urology. 2000;55:323-327.

40. Harnden P, Naylor B, Shelley MD, Clements H, Coles B, Mason MD The clinical management of patients with a small volume of prostatic cancer on biopsy: what are the risks of progression? A systematic review and meta-analysis. Cancer. 2008;112:971-981.

41. Zintzaras E, Ioannidis JP. Heterogeneity testing in meta-analysis of genome searches. Genet Epidemiol. 2005;28:123-137.

42. Lin PI, Vance JM, Pericak-Vance MA, Martin ER. No gene is an island: the flip-flop phenomenon. Am J Hum Genet. 2007;80:531-538. 


\section{Supplementary materials}

Table SI Characteristics and quality assessment of eligible studies in meta-analysis

\begin{tabular}{|c|c|c|c|c|c|c|}
\hline Study & Country & Ethnicity & Study design & $\begin{array}{l}\text { Genotyping } \\
\text { method }\end{array}$ & $\begin{array}{l}\text { Quality indicators from } \\
\text { Newcastle-Ottawa Scale }\end{array}$ & $\begin{array}{l}\text { H-w } \\
\text { test }\end{array}$ \\
\hline Taylor et al ${ }^{6}$ & USA & Caucasian, African & Hospital based & RFLP-PCR & 6 & Yes \\
\hline Kibel et al ${ }^{19}$ & USA & Caucasian, African & Hospital based & PCR-RFLP & 7 & Yes \\
\hline Ma et $\mathrm{a}^{20}$ & USA & Caucasian & $\begin{array}{l}\text { Nested in PHS } \\
\text { cohort study }\end{array}$ & PCR-RFLP & 7 & Yes \\
\hline Correa-Cerro et $\mathrm{al}^{21}$ & Germany & Caucasian & Hospital based & PCR-RFLP & 6 & Yes \\
\hline Watanabe et $\mathrm{a}^{22}$ & Japan & Asian & Hospital based & PCR-RFLP & 6 & No \\
\hline Furuya et $\mathrm{a}^{23}$ & Japan & Asian & Hospital based & PCR-RFLP & 6 & Yes \\
\hline Habuchi et $\mathrm{al}^{24}$ & Japan & Asian & Hospital based & PCR-RFLP & 6 & Yes \\
\hline Blazer et $\mathrm{a}^{25}$ & USA & Caucasian, African & Community based & PCR-RFLP & 8 & No \\
\hline Hamasaki et $\mathrm{al}^{3}$ & Japan & Asian & Hospital based & PCR-RFLP & 6 & Yes \\
\hline Medeiros et $\mathrm{a}^{26}$ & Portugal & Caucasian & Hospital based & PCR-RFLP & 6 & Yes \\
\hline Gsur et $\mathrm{al}^{27}$ & Austria & Caucasian & Hospital based & PCR-RFLP & 7 & Yes \\
\hline Tayeb et $\mathrm{a}^{28}$ & UK & Caucasian & $\begin{array}{l}\text { Selected from } \\
\text { pathology database }\end{array}$ & PCR-SSCP & 6 & Yes \\
\hline Tayeb et $\mathrm{a}^{29}$ & UK & Caucasian & Hospital based & PCR-RFLP & 6 & Yes \\
\hline Maistro et $\mathrm{al}^{30}$ & Brazil & Caucasian, African & Population based & PCR-RFLP & 6 & Yes \\
\hline Bodiwala et $\mathrm{a}^{31}$ & UK & Caucasian & Hospital based & PCR-RFLP & 6 & Yes \\
\hline Oakley-Girvan et al ${ }^{32}$ & USA & Caucasian, African & Population based & PCR-RFLP & 6 & Yes \\
\hline Huang et $\mathrm{al}^{33}$ & Taiwan & Asian & Hospital based & PCR-RFLP & 6 & Yes \\
\hline John et $\mathrm{al}^{34}$ & USA & Caucasian & Population based & PCR-RFLP & 6 & Yes \\
\hline Andersson et $\mathrm{a}^{35}$ & Sweden & Caucasian & Hospital based & PCR-RFLP & 6 & Yes \\
\hline Chaimuangraj et $\mathrm{a}^{36}$ & Thailand & Asian & Hospital based & PCR-RFLP & 6 & Yes \\
\hline Holick et $\mathrm{al}^{4}$ & USA & African, Caucasian & Population based & PCR-SSCP & 6 & Yes \\
\hline Onen et $\mathrm{a}^{37}$ & Turkey & Caucasian & Hospital based & PCR-RFLP & 6 & Yes \\
\hline Onsory et $\mathrm{al}^{38}$ & India & Indian & Hospital based & PCR-SSCP & 6 & Yes \\
\hline Rowland et al ${ }^{14}$ & American & African, Caucasian & Population based & PCR-RFLP & 6 & Yes \\
\hline Hu et $\mathrm{al}^{15}$ & $\begin{array}{l}\text { People's Republic } \\
\text { of China }\end{array}$ & Asian & Hospital based & Real-time PCR & 6 & Yes \\
\hline Yousaf et al ${ }^{16}$ & Pakistan & Asian & Hospital based & PCR-SSCP & 6 & Yes \\
\hline Jingwi et al ${ }^{17}$ & American & Caucasian & Hospital based & Real-time PCR & 6 & Yes \\
\hline
\end{tabular}

Abbreviations: $\mathrm{H}-\mathrm{w}$, Hardy-Weinberg; RFLP, restriction fragment length polymorphism; PCR, polymerase chain reaction; SSCP, single-strand conformation polymorphism.

Table S2 Distribution of Taql allele and genotype

\begin{tabular}{|c|c|c|c|c|c|c|c|c|}
\hline \multirow[t]{2}{*}{ Study } & \multirow[t]{2}{*}{ Group } & \multicolumn{3}{|c|}{ Allele } & \multicolumn{4}{|c|}{ Genotype } \\
\hline & & $\mathbf{n}$ & $\mathbf{T}$ & $\mathbf{t}$ & $\mathbf{n}$ & TT & $\mathbf{T t}$ & tt \\
\hline \multirow[t]{2}{*}{ Taylor et $\mathrm{al}^{6}$} & Case & 216 & 130 & 86 & 108 & 31 & 68 & 9 \\
\hline & Control & 340 & 187 & 153 & 170 & 54 & 79 & 37 \\
\hline \multirow[t]{2}{*}{ Kibel et al ${ }^{19}$} & Case & 82 & 54 & 28 & 41 & 19 & 16 & 6 \\
\hline & Control & 82 & 48 & 34 & 41 & 15 & 18 & 8 \\
\hline \multirow[t]{2}{*}{ Ma et $\mathrm{al}^{20}$} & Case & 744 & 454 & 290 & 372 & 134 & 186 & 52 \\
\hline & 204 control & I, I 78 & 707 & 471 & 589 & 204 & 299 & 86 \\
\hline \multirow[t]{2}{*}{ Correa-Cerro et $\mathrm{al}^{21}$} & Case & 212 & 135 & 77 & 106 & 48 & 39 & 19 \\
\hline & Control & 190 & 116 & 74 & 95 & 32 & 52 & II \\
\hline \multirow[t]{2}{*}{ Watanabe et a ${ }^{122}$} & Case & 200 & 178 & 22 & 100 & 80 & 18 & 2 \\
\hline & Control & 404 & 356 & 48 & 202 & 160 & 36 & 6 \\
\hline \multirow[t]{2}{*}{ Furuya et $\mathrm{a}^{23}$} & Case & 132 & 107 & 25 & 66 & 41 & 25 & 0 \\
\hline & Control & 120 & 100 & 20 & 60 & 41 & 18 & 1 \\
\hline \multirow[t]{2}{*}{ Habuchi et $\mathrm{al}^{24}$} & Case & 444 & 396 & 48 & 222 & 176 & 44 & 2 \\
\hline & Control & 674 & 587 & 87 & 337 & 253 & 81 & 3 \\
\hline \multirow[t]{2}{*}{ Blazer et $\mathrm{a}^{25}$} & Case & 154 & 88 & 66 & 77 & 24 & 40 & 13 \\
\hline & Control & 366 & 212 & 154 & 183 & 68 & 76 & 39 \\
\hline \multirow[t]{2}{*}{ Hamasaki et $\mathrm{al}^{3}$} & Case & 230 & 204 & 26 & 115 & 91 & 22 & 2 \\
\hline & Control & 266 & 216 & 50 & 133 & 91 & 34 & 8 \\
\hline
\end{tabular}


Table S2 (Continued)

\begin{tabular}{|c|c|c|c|c|c|c|c|c|}
\hline \multirow[t]{2}{*}{ Study } & \multirow[t]{2}{*}{ Group } & \multicolumn{3}{|c|}{ Allele } & \multicolumn{4}{|c|}{ Genotype } \\
\hline & & $\mathbf{n}$ & $\mathbf{T}$ & $\mathbf{t}$ & $\mathbf{n}$ & TT & $\mathbf{T t}$ & tt \\
\hline \multirow[t]{2}{*}{ Medeiros et $\mathrm{al}^{26}$} & Case & 324 & 195 & 129 & 162 & 52 & 91 & 19 \\
\hline & Control & 412 & 238 & 174 & 206 & 73 & 92 & $4 I$ \\
\hline \multirow[t]{2}{*}{ Gsur et $\mathrm{al}^{27}$} & Case & 380 & 227 & 153 & 190 & 71 & 85 & 34 \\
\hline & Control & 380 & 249 & $13 \mid$ & 190 & 81 & 87 & 22 \\
\hline \multirow[t]{2}{*}{ Tayeb et $\mathrm{al}^{28}$} & Case & 42 & 24 & 18 & 21 & 7 & 10 & 4 \\
\hline & Control & 758 & 453 & 305 & 379 & 136 & |8| & 62 \\
\hline \multirow[t]{2}{*}{ Tayeb et $\mathrm{al}^{29}$} & Case & 56 & 52 & 4 & 28 & 25 & 2 & 1 \\
\hline & Control & 112 & 83 & 29 & 56 & 32 & 19 & 5 \\
\hline \multirow[t]{2}{*}{ Maistro et $\mathrm{al}^{30}$} & Case & 330 & 202 & 128 & 165 & 60 & 82 & 23 \\
\hline & Control & 400 & 272 & 128 & 200 & 95 & 82 & 23 \\
\hline \multirow[t]{2}{*}{ Bodiwala et $\mathrm{al}^{31}$} & Case & 736 & 444 & 292 & 368 & 133 & 178 & 57 \\
\hline & Control & 486 & 285 & 201 & 243 & 80 & 125 & 38 \\
\hline \multirow[t]{2}{*}{ Oakley-Girvan et al ${ }^{32}$} & Case & 690 & 418 & 272 & 345 & 124 & 170 & 51 \\
\hline & Control & 584 & 365 & 219 & 292 & 115 & 135 & 42 \\
\hline \multirow[t]{2}{*}{ Huang et $\mathrm{al}^{33}$} & Case & 320 & 306 & 14 & 160 & 146 & 14 & 0 \\
\hline & Control & 410 & 384 & 26 & 205 & 179 & 26 & 0 \\
\hline \multirow[t]{2}{*}{ John et $\mathrm{al}^{34}$} & Case & 848 & 528 & 320 & 424 & 164 & 200 & 60 \\
\hline & Control & 872 & 506 & 366 & 436 & 153 & 200 & 83 \\
\hline \multirow[t]{2}{*}{ Andersson et $\mathrm{al}^{35}$} & Case & 274 & 164 & 110 & 137 & 51 & 62 & 24 \\
\hline & Control & 352 & 212 & 140 & 176 & 67 & 78 & 31 \\
\hline \multirow[t]{2}{*}{ Chaimuangraj et $\mathrm{al}^{36}$} & Case & 56 & 50 & 6 & 28 & 22 & 6 & 0 \\
\hline & Control & 148 & 132 & 16 & 74 & 59 & 14 & I \\
\hline \multirow[t]{2}{*}{ Holick et $\mathrm{al}^{4}$} & Case & $\mathrm{I}, \mathrm{I} 72$ & 730 & 442 & 586 & 238 & 254 & 94 \\
\hline & Control & 1,090 & 648 & 442 & 545 & 188 & 272 & 85 \\
\hline \multirow[t]{2}{*}{ Onen et $\mathrm{al}^{37}$} & Case & 266 & 180 & 86 & 133 & 62 & 56 & 15 \\
\hline & Control & 314 & 189 & 125 & 157 & 57 & 75 & 25 \\
\hline \multirow[t]{2}{*}{ Onsory et $\mathrm{al}^{38}$} & Case & 200 & 150 & 50 & 100 & 55 & 40 & 5 \\
\hline & Control & 200 & 134 & 66 & 100 & 43 & 48 & 9 \\
\hline \multirow[t]{2}{*}{ Rowland et $\mathrm{al}^{14}$} & Case & 3,252 & 2,172 & 1,080 & 1,626 & 732 & 708 & 186 \\
\hline & Control & 2,144 & $\mathrm{I}, 376$ & 768 & $\mathrm{I}, 072$ & 451 & 474 & 147 \\
\hline \multirow[t]{2}{*}{ Hu et $\mathrm{al}^{15}$} & Case & 216 & 202 & 14 & 108 & 96 & 10 & 2 \\
\hline & Control & 484 & 460 & 24 & 242 & 219 & 22 & I \\
\hline \multirow[t]{2}{*}{ Yousaf et al ${ }^{16}$} & Case & 88 & 67 & 21 & 44 & 27 & 13 & 4 \\
\hline & Control & 238 & 163 & 75 & 119 & 76 & 11 & 32 \\
\hline \multirow[t]{2}{*}{ Jingwi et al ${ }^{17}$} & Case & 612 & $45 I$ & 161 & 306 & 170 & III & 25 \\
\hline & Control & 502 & 325 & 177 & $25 I$ & 105 & 115 & 31 \\
\hline
\end{tabular}

\section{Publish your work in this journal}

OncoTargets and Therapy is an international, peer-reviewed, open access journal focusing on the pathological basis of all cancers, potential targets for therapy and treatment protocols employed to improve the management of cancer patients. The journal also focuses on the impact of management programs and new therapeutic agents and protocols on patient perspectives such as quality of life, adherence and satisfaction. The manuscript management system is completely online and includes a very quick and fair peer-review system, which is all easy to use. Visit http://www.dovepress.com/testimonials.php to read real quotes from published authors. 